\title{
Superior Mechanical Properties and Work-Hardening Ability of Ultrafine-Grained Quenched and Partitioned Steels Processed by a Novel Approach Involving Asymmetric Hot Rolling
}

\author{
Zhengyou Tang ${ }^{1, *}$, Jianeng Huang ${ }^{1, *}$, Xingchao Lu ${ }^{1}$, Hua Ding ${ }^{1}$, Dongmei Zhang ${ }^{2}$ and \\ Devesh Misra ${ }^{3, *}$ \\ 1 School of Materials Science and Engineering, Northeastern University, Shenyang 110819, China; \\ 15040279961@163.com (X.L.); neutangzy@sina.com (H.D.) \\ 2 Shenyang Liming Aero-Engine Corporation, AECC, Shenyang 110043, China; melbtangzy@126.com \\ 3 Laboratory for Excellence in Advanced Steel Research, Department of Metallurgical, \\ Materials and Biomedical Engineering, University of Texas at El Paso, El Paso, TX 79968, USA \\ * Correspondence: tangzy@smm.neu.edu.cn (Z.T.); Huangjnd@163.com (J.H.); dmisra2@utep.edu (D.M.); \\ Tel.: +1-(915)-747-8679 (D.M.)
}

Received: 8 October 2018; Accepted: 23 October 2018; Published: 25 October 2018

\begin{abstract}
An approach is proposed to enhance the mechanical properties and work-hardening (WH) ability of low-alloy steels. Using asymmetric hot rolling (AHR) and subsequent direct quenching (DQ) prior to the quenching and partitioning $(\mathrm{Q} \& \mathrm{P})$ process, an ultrafine-grained Q\&P steel with excellent combination of tensile strength of $\sim 1000 \mathrm{MPa}$ and total elongation of $\sim 35 \%$ was obtained, which exhibited high WH exponent at higher strain induced by the higher volume fraction and higher stability of film-like retained austenite located between the martensite laths.
\end{abstract}

Keywords: low-alloy; Q\&P steel; mechanical property; work-hardening; ultrafine grain

\section{Introduction}

Quenching and partitioning $(\mathrm{Q} \& \mathrm{P})$ steel has been the focus in recent years to obtain excellent a combination of strength and plasticity [1-3]. Mechanical properties of Q\&P steel are related to the work-hardening $(\mathrm{WH})$ rate induced by austenite-to-martensite transformation during deformation [3-6]. The quantity and stability of the retained austenite (RA) in Q\&P steels plays an important role, which depends not only on the chemical composition and heat treatment, but also on the original microstructure prior to the Q\&P process. Ultrafine-grained (UFG) structure and using martensite as the prior microstructure prior to Q\&P process has been considered [4,7-10]. However, in the UFG Q\&P steel, the ductility is deteriorated and the work-hardening ability during plastic deformation is not increased [11-13]. Thus, it is relevant to develop novel methods to ensure excellent mechanical properties and work-hardening ability in UFG Q\&P steel.

Asymmetric rolling is a new, easy, and inexpensive plastic deformation technique, and it is suitable for producing large structural components with UFG [14,15]. Asymmetric hot rolling (AHR) is especially useful, because it can increase shear strain when the hot-rolled steel plates are relatively thick and friction is high during AHR [16,17]. The traditional process of cold-rolled Q\&P steels consists of conventional hot rolling (CHR), cold rolling and Q\&P heat treatment $[1-3,6]$. Recently, a few studies indicated superior stability of film-like RA, which can be obtained using martensite as the prior microstructure prior to Q\&P process $[4,7]$. However, the martensite prior microstructure heat treatment mainly focused on hot-rolling off-line quenching. Compared with this quenching, the direct 
quenching (DQ) after AHR is relatively simpler and energy-efficient. Simultaneously, cold rolling of martensite requires significantly less strain to obtain UFG for low-alloy steels [11,18].

The study described here focuses on a novel approach by combining AHR, followed by DQ and Q\&P process, to significantly enhance the mechanical properties and work-hardening ability of low-alloy steel using deformed martensite as the prior microstructure of the Q\&P process. The product of tensile strength and total elongation (PSE) of the low-alloy UFG Q\&P steel was greater than $35.8 \mathrm{GPa} \%$, approaching PSE $\geq 30 \mathrm{GPa} \%$ in 3rd generation high-alloy automotive steels [19-21]. Additionally, the effect of volume fraction, grain size, morphology, and location of RA on work-hardening behaviors is explored.

\section{Experimental}

The composition of the experimental steel was Fe-0.2C-1.5Mn-1.3Si-0.2Al (wt.\%). A $50 \mathrm{~kg}$ ingot was cast after melting in a vacuum induction furnace, which was hot forged to slabs with width of $100 \mathrm{~mm}$ and thickness of $30 \mathrm{~mm}$. To design an appropriate AHR and Q\&P process, the critical temperatures of $A_{c 1}, A_{c 3}, M_{s}$ and $M_{f}$ measured by dilatometry were $740{ }^{\circ} \mathrm{C}, 900{ }^{\circ} \mathrm{C}, 360{ }^{\circ} \mathrm{C}$ and $280{ }^{\circ} \mathrm{C}$, respectively. To obtain different hot-rolled microstructures, the specimens were divided into three groups, referred as CHR-Q\&P steel, AHR-Q\&P steel and AHR-DQ-Q\&P steel, respectively. The three groups of steels were all soaked at $1200{ }^{\circ} \mathrm{C}$ for $2 \mathrm{~h}$ and then hot rolled to sheets with thickness of $3 \mathrm{~mm}$ after nine pass rollings with start and finish temperatures of $1150^{\circ} \mathrm{C}$ and $910^{\circ} \mathrm{C}$, respectively. Subsequently, these CHR-Q\&P and AHR-Q\&P sheets were air cooled and AHR-DQ-Q\&P sheets were directly quenched to room temperature after hot finish rolling. Next all sheets were cold rolled to strips with thickness of $1.0 \mathrm{~mm}$ after pickling in $10 \%$ hydrochloric acid. The Q\&P heat treatments of all cold-rolled strips were identical and were conducted in salt bath, which were intercritically austenitized at $820^{\circ} \mathrm{C}$ for $5 \mathrm{~min}$, and then immediately quenched to $260^{\circ} \mathrm{C}$ for $5 \mathrm{~s}$, followed by holding at $400{ }^{\circ} \mathrm{C}$ for duration of $200 \mathrm{~s}$ and air cooled to room temperature. AHR was carried out using a $\Phi 400-\mathrm{mm}$ two-roll reversible rolling mill ( $\Phi 400$, Shenyang, China). The velocity ratio of 1.1 was achieved via different circumferential velocities of two working rolls with same diameters but different rotational speed. Tensile tests were performed on specimens of a gauge width of $12.5 \mathrm{~mm}$ and a gauge length of $50 \mathrm{~mm}$ using a SANSCMT-5000 (MTS, Eden prairie, MN, USA) tensile machine at a constant crosshead speed of $2 \mathrm{~mm} \cdot \mathrm{min}^{-1}$ at room temperature. Of which, the Tensile specimens were machined from the heat-treated sheets with the tensile axis parallel to the prior rolling direction. The microstructures were studied by optical microscope (OM, OLYMPUS-GSX500, OLYMPUS, Tokyo, Japan), scanning electron microscopy (SEM, Supra, SSX-550, Shimadzu, Tokyo, Japan) and transmission electron microscope (TEM, TECNAI G2-20, operated at $200 \mathrm{kV}$, FEI, Hillsboro, OR, USA). The volume fraction of retained austenite $\left(f_{\mathrm{RA}}\right)$ was measured by $\mathrm{X}$-ray diffraction using $\mathrm{Cu}-\mathrm{K} \alpha$ radiation. Integrated intensities of diffraction peak (200) $\alpha,(211) \alpha,(200) \gamma,(220) \gamma$ and (311) $\gamma$ were calculated, and the $f_{\text {RA }}$ was calculated based on direct comparison method $[22,23]$. The work-hardening behavior was studied using instantaneous work-hardening exponent, $\mathrm{n}=(\varepsilon / \sigma) \cdot(\mathrm{d} \sigma / \mathrm{d} \varepsilon)$, which was deduced from Hollomon equation [24]. Additional interrupted tensile tests at different strain corresponding to typical $n$ value were carried out to estimate the extent of strain-induced transformation of austenite to martensite using XRD (Rigaku, D/Max2250/PC, Rigaku Corporation, Tokyo, Japan) studies.

\section{Results and Discussion}

The resulting microstructure of samples is shown in Figure 1. After hot rolling and air cooling, the CHR-Q\&P steel and AHR-Q\&P steel both showed a typical ferrite and pearlite microstructure, as shown in Figure 1a,b. In the CHR-Q\&P steel, pearlite banding was observed parallel to the rolling direction (RD), but in the AHR-Q\&P steel, the pearlite banding was broken and was present in a non-continuous manner. AHR refined the grain size. After AHR and DQ, the as-direct quenched microstructure of AHR-DQ-Q\&P steel is shown in Figure 1c, which exhibits a typical martensitic microstructure. Resulting final microstructure of subsequent Q\&P process are shown in Figure $1 \mathrm{~d}-\mathrm{f}$. 
In the SEM micrographs, ferrite appears black, while martensite appears light grey. It is difficult to make a clear distinction between RA and matrix in the SEM micrographs. The microstructural constituent consisted of equiaxed grains of intercritical ferrite surrounded by martensite and RA. In contrast, as is shown in Figure $1 \mathrm{~d}-\mathrm{f}$, the average ferrite grain size of the three samples are about $3.5 \mu \mathrm{m}, 1.2 \mu \mathrm{m}$ and $0.8 \mu \mathrm{m}$, respectively. The best refined microstructure was present in AHR-DQ-Q\&P steel, followed by AHR-Q\&P steel and CHR-Q\&P steel.

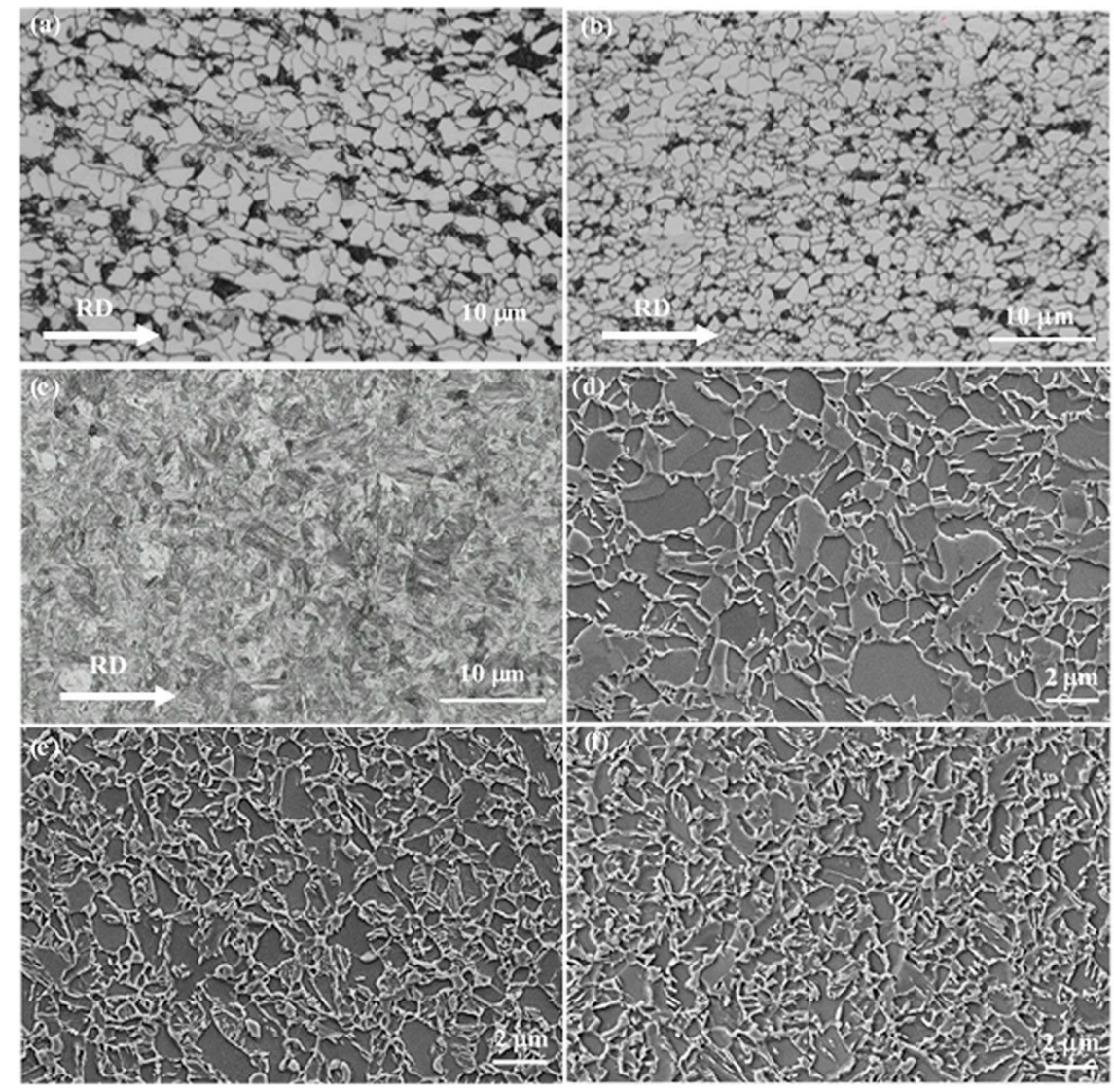

Figure 1. OM and SEM micrographs of microstructures. OM micrographs of (a) as-air cooled microstructure after CHR for CHR-Q\&P steel, (b) as-air cooled microstructure after AHR for AHR-Q\&P steel, (c) as-direct quenched microstructure after AHR for AHR-DQ-Q\&P steel; SEM micrographs of final microstructures for (d) CHR-Q\&P, (e) AHR-Q\&P and (f) AHR-DQ-Q\&P samples.

Figure 2 shows TEM result of samples pertaining to CHR-Q\&P, AHR-Q\&P and AHR-DQ-Q\&P processes. As shown in Figure 2a,b, the microstructure including ferrite and RA of AHR-Q\&P steel were significantly refined than CHR-Q\&P steel. Compared with the CHR process, the AHR process refines the microstructure. Furthermore, in contrast, as is shown in Figure $2 \mathrm{a}-\mathrm{c}$, the AHR-DQ process not only effectively refined the microstructure, but also changed the RA morphology. Blocky RA was observed in CHR-Q\&P and AHR-Q\&P steel (Figure 2a,b). However, the morphology of RA in the AHR-DQ-Q\&P steel was mainly present as a film (Figure 2c). For the AHR-DQ-Q\&P steel, Figure 2d-f show bright and dark-field TEM images of film-like morphology RA and the selected area diffraction pattern (SADP), shows the orientation relationship between film-like RA and lath martensite, and was Kurdjumov-Sachs (K-S) relationship. The cold-rolled structure of AHR-DQ martensite was further studied by TEM as shown in Figure $2 \mathrm{~g}-\mathrm{i}$. The corresponding SADP in Figure $2 \mathrm{i}$ exhibited ring-like pattern, indicating that grain subdivision occurred and the presence of very high density of dislocations during cold-rolled deformation (Figure $2 \mathrm{~g}, \mathrm{~h}$ ).

It is proposed that the reasons for the refinement of microstructure (Figures 1 and $2 \mathrm{a}-\mathrm{c}$ ), increasing of $f_{\text {RA }}$ (Table 1) and change of RA morphology (Figure 2a-f) are related to AHR and subsequent DQ 
prior to Q\&P process. Compared to CHR, extra shear strain can be introduced into the steel plate by applying AHR, which can influence the microstructural evolution by increasing the total value of effective strain, and the final hot-rolled microstructure is refined [17]. In this study, the temperature of $\gamma-\alpha$ transformation $\left(A_{r 3}\right)$ and non-recrystallization temperature (Tnr) of steel was measured to be $730^{\circ} \mathrm{C}$ and $945^{\circ} \mathrm{C}$ by Gleeble 1500 thermo-mechanical simulator. To measure non-recrystallization temperature (Tnr), samples $10 \mathrm{~mm}$ diameter and $15 \mathrm{~mm}$ long were used for hot-rolled process simulations after cutting from hot-forged slab. The process schedule is involved: reheating for $5 \mathrm{~min}$ at $1200{ }^{\circ} \mathrm{C}$; roughing deformation up to 0.35 strain at $1 \mathrm{~s}^{-1}$ strain rate at $1100{ }^{\circ} \mathrm{C}$; cooling at $1{ }^{\circ} \mathrm{C}$ $\mathrm{s}^{-1}$ to each of deformation temperatures between 900 and $1000{ }^{\circ} \mathrm{C}$, finishing deformation up to a strain of 0.60 at a strain rate of $1 \mathrm{~s}^{-1}$, followed by either water quenching to room temperature. All samples were examined using optical microscopy to confirm the recrystallization. The present CHR and AHR initial 8 passes were above Tnr and finish rolling pass was below Tnr. The extra shear strain above $T n r$ increases the rate of recrystallization, and reduces the recrystallized grain size. The extra shear strain below $T n r$ increases the ferrite nucleation rate of AHR-Q\&P steel or martensite nucleation rate of AHR-DQ-Q\&P steel. Thus, AHR refines the hot-rolled microstructure as shown in Figure 1a-c, which agrees with the literature $[25,26]$.

The AHR and the subsequent DQ are beneficial to obtain fine martensitic microstructure (Figure 1c), which is favorable to the achievement of fine microstructure after cold rolling and Q\&P treatment. Furthermore, cold rolling of martensite requires significantly less strain to obtain UFG structure [27]. The rapid grain subdivision and a very high density of dislocation (Figure $2 \mathrm{~g}, \mathrm{~h}$ ) after cold rolling with a reduction of $\sim 67 \%$ is attributed to fine and hierarchical structure of martensite [11]. Thus, the deformation structure due to AHR and subsequent DQ prior to Q\&P process was sufficiently refined, which was beneficial in obtaining UFG microstructure.

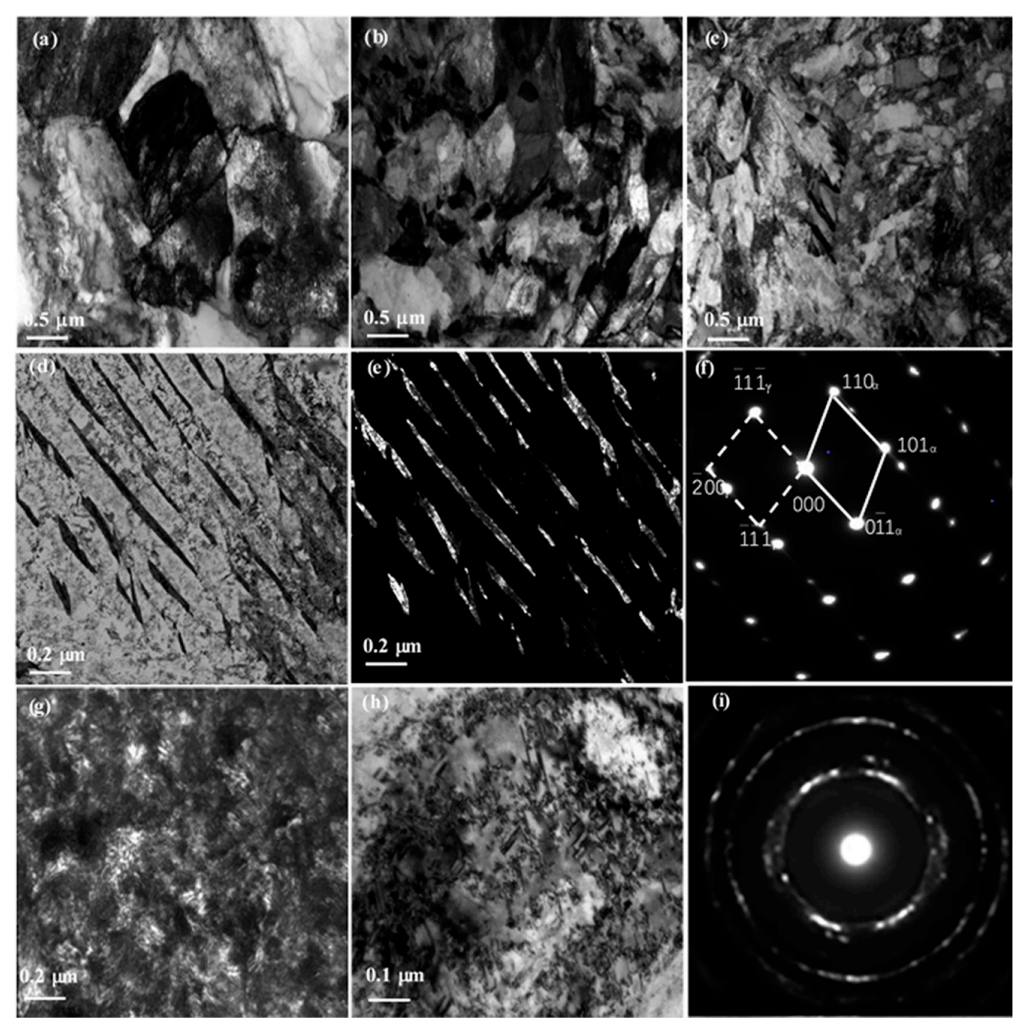

Figure 2. TEM images of final microstructures for (a) CHR-Q\&P, (b) AHR-Q\&P and (c) AHR-DQ-Q\&P steel; (d-f) TEM images of final microstructures for AHR-DQ-Q\&P steel, (d) bright-field TEM images of film-like morphology retained austenite (RA), (e) dark-field TEM images and (f) selected area diffraction pattern (SADP); (g-i) TEM images of cold-rolled martensite for AHR-DQ-Q\&P steel, (g) cold-rolled martensite, (h) enlargement of selected area in (d), (i) corresponding to SADP. 
It is interesting to note that by applying AHR and subsequent DQ prior to Q\&P process, a total volume fraction of $18.5 \%$ (Table 1), smaller grain size and stable RA with film-like morphology was obtained. The blocky RA that usually exists treated by Q\&P process after intercritical austenitization was suppressed (Figure 2a-f). During intercritical annealing, austenite islands were formed in the matrix, the carbide particles dissolved in austenite and enriched with $\mathrm{C}$ and Mn. Furthermore, small austenite islands can also impose a strong pinning effect on ferrite sub-grain boundaries and grain boundaries, which can retard the boundary migration and recrystallization of ferrite [28,29]. In this study, when the fine martensite prior to Q\&P process was cold rolled, the stored energy after deformation was higher and formation of small austenite islands was promoted. At the same time, in low-alloy steels, in which the martensitic microstructure partially reaustenitizes in the intercritical region, two types of austenite will form during annealing, i.e., interlath/acicular austenite forms at martensite lath boundaries and blocky austenite mainly at the prior austenite grain boundaries $[7,11]$. Accordingly, the finer grained austenite structure will result in a higher share of secondary martensite containing more carbon and thus being stronger [30,31]. After quenching to $260{ }^{\circ} \mathrm{C}$ during Q\&P process, film-like and blocky morphology RA are preserved, which correspond to interlath/acicular austenite and blocky austenite in the intercritical region. Subsequently, during partitioning at $400{ }^{\circ} \mathrm{C}$, because the film-like RA is more stable than the blocky RA, and blocky RA is difficult to be homogeneously enriched in carbon [32,33]. Thus, majority of the blocky RA transform to new martensite, while a considerable amount of film-like RA is retained at room temperature.

AHR and subsequent DQ prior to Q\&P process, is the primary reason for AHR-DQ-Q\&P steel exhibiting excellent mechanical properties (Table 1) and work-hardening ability (Figure 3). The engineering stress-strain curves for CHR-Q\&P, AHR-Q\&P and AHR-DQ-Q\&P steel are presented in Figure 3a. The three groups of steels exhibited continuous yielding, which is desirable to control surface defects during metal sheet forming. The mechanical properties of steels are presented in Table 1. AHR led to increase of yield stress (YS) (because of the finer grains) and slight increase of UTS and TEL. PSE of AHR-Q\&P (air cooling after AHR) steel was greater than $28 \mathrm{GPa} \%$. Comparing air cooled specimens after AHR, it is interesting to note that UFG Q\&P steel using DQ after AHR showed not only better YS but also a better combination of UTS and TEL. The sample referred as AHR-DQ-Q\&P steel was characterized by an excellent combination of UTS of $1023 \mathrm{MPa}$, TEL of 35\%, and PSE of 35 GPa\%.

Table 1. Mechanical properties of experimental steels.

\begin{tabular}{cccccc}
\hline Sample & YS (MPa) & UTS (MPa) & TEL (\%) & UTS $\times$ TEL (GPa\%) & $f_{\text {RA }}$ (Vol.\%) \\
\hline CHR-Q\&P & $495( \pm 10)$ & $963( \pm 15)$ & $28( \pm 0.3)$ & $26.9( \pm 0.2)$ & 12.1 \\
AHR-Q\&P & $537( \pm 8)$ & $978( \pm 10)$ & $29( \pm 0.2)$ & $28.3( \pm 0.2)$ & 15.0 \\
AHR-DQ-Q\&P & $605( \pm 12)$ & $1023( \pm 17)$ & $35( \pm 0.3)$ & $35.8( \pm 0.3)$ & 18.5 \\
\hline
\end{tabular}

Figure $3 b$ shows variation in instantaneous WH exponent with true strain. It is obvious that the WH behavior can be divided into three stages, i.e., the instantaneous WH exponent of CHR-Q\&P and AHR-Q\&P steel rapidly decrease during early stages of tensile deformation in stage I, then slightly decrease in stage II, before finally rapidly decreasing again until failure in stage III with increased true strain. It is interesting to note that the WH behavior of AHR-DQ-Q\&P steel is different from the other two kinds of steels, the instantaneous WH exponent slightly increases in stage II, and sustains a longer stage until the peak stress (UTS). 

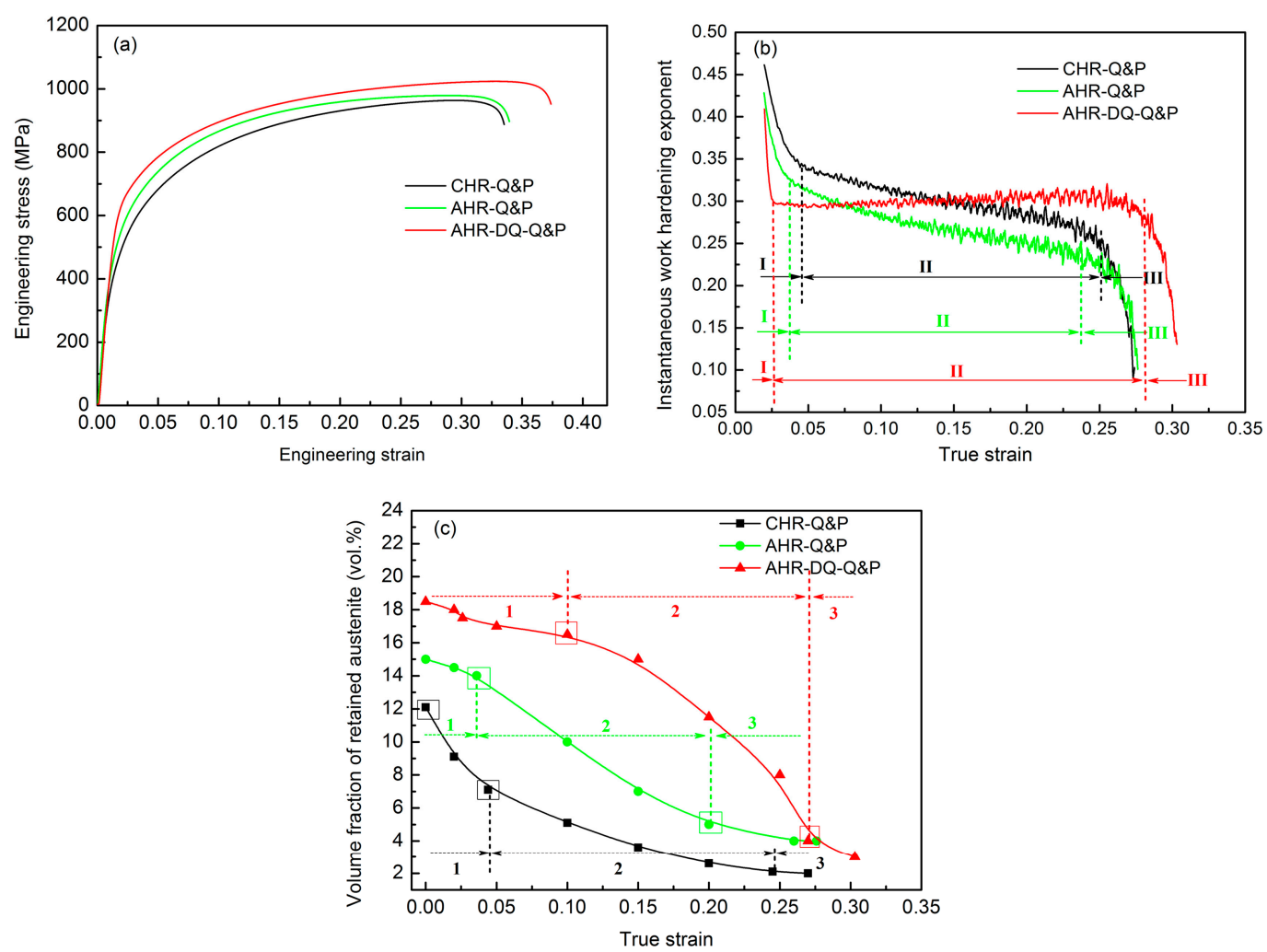

Figure 3. Engineering stress-strain curves of samples at room temperature (a), variation in instantaneous work-hardening exponents with true strain $(\mathbf{b})$ and volume fraction of retained austenite as a function of engineering strain (c) for CHR-Q\&P, AHR-Q\&P and AHR-DQ-Q\&P steel.

The evolution of $f_{\mathrm{RA}}$ during tensile tests is shown in Figure $3 \mathrm{c}$. The $f_{\mathrm{RA}}$ change can be also divided into three stages. AHR-DQ-Q\&P steel had higher $f_{\text {RA }}$ before tensile deformation. However, during deformation, the three kinds of steels exhibited different trend in $f_{\mathrm{RA}}$. In stage 1 , the $f_{\mathrm{RA}}$ change of CHR-Q\&P steel is rapid, AHR-Q\&P and AHR-DQ-Q\&P steels show a slow decreasing rate. In stage 2, AHR-Q\&P and AHR-DQ-Q\&P steels indicated a rapid decreasing rate, in contrast to CHR-Q\&P steel. In stage 3, AHR-DQ-Q\&P steel exhibited a slow decreasing rate, CHR-Q\&P and AHR-Q\&P steels showed an almost no change in trend.

The observed difference in mechanical properties and WH behavior can be explained in terms of different $f_{\text {RA, }}$ morphology, location, and grain size of RA. First, compared with CHR-Q\&P and AHR-Q\&P steels, the initial $f_{\text {RA }}$ was higher in AHR-DQ-Q\&P steel, which still had some RA that can transform at high strains, whereas the other two steels had exhausted its RA because of the transformation-induced plasticity (TRIP) effect (Figure 3c). Second, blocky austenite was surrounded by ferrite in CHR-Q\&P and AHR-Q\&P steel (Figure 2a,b), while film-like RA was located between martensite laths in AHR-DQ-Q\&P steel (Figure 2c-f). It is well known that film-like RA has better stability compared to the blocky shape, and the latter tends to transform to martensite at a small strain and contributes less the TRIP effect [7,34]. At the same time, ferrite is ductile and soft, and withstands more strain during tension especially at low strain. The harder martensite phase bears more stress, which can "shield" RA during deformation and make RA transform at high strain [3,35]. Consequently, AHR-DQ-Q\&P steel exhibited high WH exponent, TEL and UTS at higher strain induced by the higher volume fraction and higher stability of film-like retained austenite located between the martensite laths (Figure 3b).

We compared the mechanical performance of AHR-DQ-Q\&P steel to other advanced high strength steels (AHSS) in literature [36-39] in Figure 4. By AHR and subsequent DQ prior to Q\&P process, AHR-DQ-Q\&P steel not only exhibited significantly higher PSE than conventional AHSS, but also exhibited significantly higher UTS and larger TEL than other convectional TRIP (C-TRIP) 
steel, dual phase (DP) steel and complex phase (CP) steel in the region of the first generation AHSS. Moreover, it exhibited higher TEL than medium Mn (M-Mn) steel, Q\&P steel and carbide-free bainite (CFB) steel in the region of the third-generation AHSS. Simultaneously, it exhibited slightly higher PSE than deformed and partitioned (D\&P) steel [39]. Although its PSE is lower than that of the third-generation steel mainly including twinning-induced plasticity (TWIP) steels, its weight fraction of alloying element is decreased, and the price is relatively cheap. Consequently, our AHR-DQ-Q\&P steel achieves excellent tensile properties and defined a new region above the PSE line of $30 \mathrm{GPa} \%$ in the strength-ductility map (Figure 4). Not only tensile strength of $\sim 1000 \mathrm{MPa}$, the excellent PSE of $\sim 35 \mathrm{GPa} \%$ in our AHR-DQ-Q\&P steel makes it a desirable alloy for applications where PSE is the main design criterion, which is rather remarkable for a low-alloy steel.

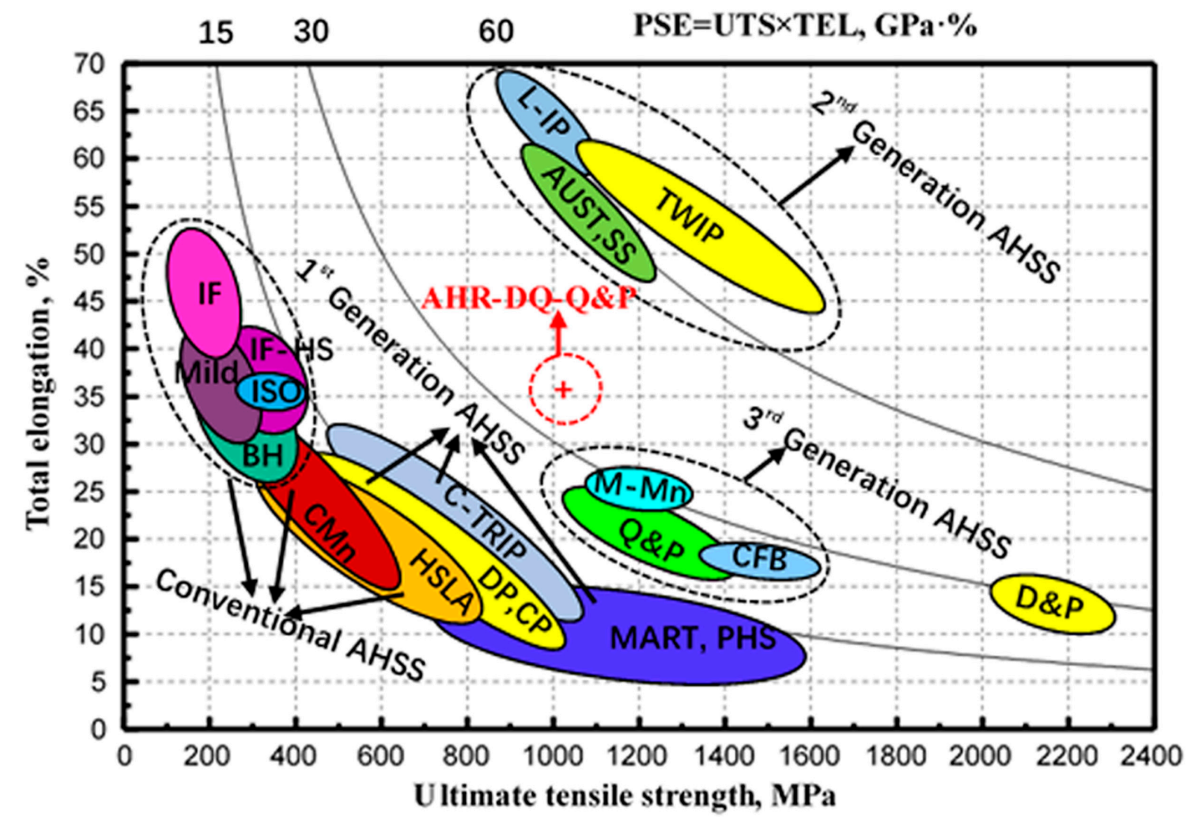

Figure 4. Summary of mechanical performance of those existing advanced high strength steels (AHSS) reported in the literature as compared to the investigated steel.

\section{Conclusions}

In summary, a novel approach to ensure excellent mechanical properties and work-hardening ability is proposed. Compared with CHR-Q\&P and AHR-Q\&P steel, UFG AHR-DQ-Q\&P steel was obtained by AHR and subsequent DQ prior to Q\&P process, which was beneficial in refining the microstructure, increase $f_{\mathrm{RA}}$ and change RA morphology from blocky to film-like. Consequently, AHR-DQ-Q\&P steel was characterized by an excellent combination of UTS of $1023 \mathrm{MPa}$, TEL of $35 \%$ and PSE of $\sim 35 \mathrm{GPa} \%$, and higher WH exponent at higher strain caused by the higher volume fraction and stability of RA. However, considering a $67 \%$ cold reduction for DQ (martensitic) hot strip in an industrial mill probably leads to overloading of the rolling stands. Therefore, further study of the proposed process is needed in industry.

Author Contributions: Z.T. and J.H. designed most of the experiments, performed most experiments, analyzed the results and wrote this manuscript. X.L., H.D., D.Z. and D.M. helped analyze the experiment data and gave some constructive suggestions about how to write this manuscript.

Acknowledgments: The research was supported by the National Natural Science Foundation of China (Grant No. 51574077, No. 51874088) and Fundamental Research Funds for the Central Universities (N120502005). D.M. acknowledges continued collaboration with Northeastern University as Honorary Professor in providing guidance to students in research, and support from National Science foundation, USA via grant DMR.

Conflicts of Interest: The authors declare no conflict of interest. 


\section{References}

1. Speer, J.G.; Matlock, D.K.; De Cooman, B.C.; Schroth, J.G. Carbon partitioning into austenite after martensite transformation. Acta Mater. 2003, 51, 2611-2622. [CrossRef]

2. Speer, J.G.; Edmonds, D.V.; Rizzo, F.C.; Matlock, D.K. Partitioning of carbon from supersaturated plates of ferrite, with application to steel processing and fundamentals of the bainite transformation. Solid State Mater. Sci. 2004, 8, 219-237. [CrossRef]

3. Xiong, X.C.; Chen, B.; Huang, M.X.; Wang, J.F.; Wang, L. The effect of morphology on the stability of retained austenite in a quenched and partitioned steel. Scr. Mater. 2013, 68, 321-324. [CrossRef]

4. Zhang, J.; Ding, H.; Misra, R.D.K.; Wang, C. Enhanced stability of retained austenite and consequent work hardening rate through pre-quenching prior to quenching and partitioning in a Q-P microalloyed steel. Mater. Sci. Eng. A 2014, 611, 252-256. [CrossRef]

5. Li, W.S.; Gao, H.Y.; Nakashima, H.; Hata, S.; Tian, W.H. In-situ EBSD study of deformation behavior of retained austenite in a low-carbon quenching and partitioning steel via uniaxial tensile tests. Mater. Charact. 2016, 118, 431-437. [CrossRef]

6. Zhao, H.S.; Li, W.; Zhu, X.; Lu, X.H.; Wang, L.; Zhou, S.; Jin, X.J. Analysis of the relationship between retained austenite locations and the deformation behavior of quenching and partitioning treated steels. Mater. Sci. Eng. A 2016, 649, 18-26. [CrossRef]

7. Ding, R.; Tang, D.; Zhao, A. A novel design to enhance the amount of retained austenite and mechanical properties in low-alloyed steel. Scr. Mater. 2014, 88, 21-24. [CrossRef]

8. Santofimia, M.J.; Nguyen-Minh, T.; Zhao, L.; Petrov, R.; Sabirov, I.; Sietsma, J. New low carbon Q\&P steels containing film-like intercritical ferrite. Mater. Sci. Eng. A 2010, 527, 6429-6439.

9. Sugimoto, K.I.; Muramatsu, T.; Hashimoto, S.I.; Mukai, Y. Formability of Nb bearing ultra high-strength TRIP-aided sheet steels. J. Mater. Process. Technol. 2006, 177, 390-395. [CrossRef]

10. Sugimoto, K.I.; Mizuno, Y.; Natori, M.; Hojo, T. Effects of fine particle peening on fatigue strength of a TRIP-aided martensitic steel. Int. J. Fatigue 2017, 100, 206-214. [CrossRef]

11. Ding, R.; Tang, D.; Zhao, A.; Guo, H.; He, J.H.; Zhi, C. Effect of ultragrain refinement on quenching and partitioning steels manufactured by a novel method. Mater. Des. 2015, 87, 640-649. [CrossRef]

12. Song, R.; Ponge, D.; Raabe, D.; Speer, J.G.; Matlock, D.K. Overview of processing, microstructure and mechanical properties of ultrafine grained bcc steels. Mater. Sci. Eng. A 2006, 441, 1-17. [CrossRef]

13. Lee, S.; Lee, S.J.; De Cooman, B.C. Work hardening behavior of ultrafine-grained Mn transformation-induced plasticity steel. Acta Mater. 2011, 59, 7546-7553. [CrossRef]

14. Duan, Y.L.; Xu, G.F.; Tang, L.; Liu, Y.; Xu, J.W.; Deng, Y.; Yin, Z.M. Excellent high strain rate superplasticity of Al-Mg-Sc-Zr alloy sheet produced by an improved asymmetrical rolling process. J. Alloys Compd. 2017, 715, 311-321. [CrossRef]

15. Wronski, S.; Bacroix, B. Microstructure evolution and grain refinement in asymmetrically rolled aluminium. Acta Mater. 2014, 76, 404-412. [CrossRef]

16. Ma, B.; Li, C.S.; Song, Y.L.; Wang, J.K.; Sui, F.L. Deformation and recrystallization microtextures of an austenitic steel during asymmetrical hot rolling process. J. Mater. Sci. 2017, 52, 13212-13226. [CrossRef]

17. Chen, S.; An, Y.G.; Lahaije, C. Toughness improvement in hot rolled HSLA steel plates through asymmetric rolling. Mater. Sci. Eng. A 2015, 625, 374-379. [CrossRef]

18. Ueji, R.; Tsuji, N.; Minamino, Y.; Koizumi, Y. Ultragrain refinement of plain low carbon steel by cold-rolling and annealing of martensite. Acta Mater. 2002, 50, 4177-4189. [CrossRef]

19. Lee, S.W.; Lee, S.J.; Cooman, B.C.D. Austenite stability of ultrafine-grained transformation-induced plasticity steel with Mn partitioning. Scr. Mater. 2011, 65, 225-228. [CrossRef]

20. Shi, J.; Sun, X.J.; Wang, M.Q.; Hui, W.J.; Dong, H.; Cao, W.Q. Enhanced work-hardening behavior and mechanical properties in ultrafine-grained steels with large-fractioned metastable austenite. Scr. Mater. 2010, 63, 815-818. [CrossRef]

21. Aydin, H.; Essadiqi, E.; Jung, I.H.; Yue, S. Development of 3rd generation AHSS with medium Mn content alloying compositions. Mater. Sci. Eng. A 2013, 564, 501-508. [CrossRef]

22. Wang, Z.C.; Kim, S.J.; Lee, C.G.; Lee, T.H. Bake-hardening behavior of cold-rolled CMnSi and CMnSiCu TRIP-aided steel sheets. J. Mater. Process. Technol. 2004, 151, 141-145. [CrossRef] 
23. Li, Z.; Wu, D. Effects of Hot Deformation and Subsequent Austempering on the Mechanical Properties of Si-Mn TRIP Steels. ISIJ Int. 2006, 46, 121-128. [CrossRef]

24. Tang, Z.Y.; Huang, J.N.; Ding, H.; Cai, Z.H.; Misra, R.D.K. Austenite stability and mechanical properties of a low-alloyed ECAPed TRIP-aided steel. Mater. Sci. Eng. A 2018, 724, 95-102. [CrossRef]

25. Orlovc, D.; Lapovok, R.; Tóth, L.S.; Timokhina, I.B.; Hodgson, P.D.; Bhattacharjee, D.; Haldar, A. Development of Asymmetric Rolling for the Better Control over Structure and Mechanical Properties in IF Steel. Mater. Sci. Forum 2012, 2788, 706-709.

26. Lee, K.M.; Lee, H.C. Grain refinement and mechanical properties of asymmetrically rolled low carbon steel. J. Mater. Process. Technol. 2010, 210, 1574-1579. [CrossRef]

27. Zakerinia, H.; Kermanpur, A.; Najafizadeh, A. The effect of bainite in producing nano/ultrafine grained steel by the martensite treatment. Mater. Sci. Eng. A 2011, 528, 3562-3567. [CrossRef]

28. Hamzeh, M.; Kermanpur, A.; Najafizadeh, A. Fabrication of the ultrafine-grained ferrite with good resistance to grain growth and evaluation of its tensile properties. Mater. Sci. Eng. A 2014, 593, 24-30. [CrossRef]

29. Karmakar, A.; Sivaprasad, S.; Nath, S.K.; Misra, R.D.K.; Chakrabarti, D. Comparison Between Different Processing Schedules for the Development of Ultrafine-Grained Dual-Phase Steel. Metall. Mater. Trans. A 2014, 45, 2466-2479. [CrossRef]

30. Pous-Romero, H.; Lonardelli, I.; Cogswell, D.; Bhadeshia, H.K.D.H. Austenite grain growth in a nuclear pressure vessel steel. Mater. Sci. Eng. A 2013, 567, 72-79. [CrossRef]

31. Yi, H.L.; Lee, K.Y.; Bhadeshia, H.K.D.H. Mechanical stabilisation of retained austenite in $\delta$-TRIP steel. Mater. Sci. Eng. A 2011, 528, 5900-5903. [CrossRef]

32. Bhadeshia, H.K.D.H.; Edmonds, D.V. Bainite in silicon steels: new composition-property approach Part 1. Met. Sci. 1983, 17, 411-419. [CrossRef]

33. Guo, H.; Zhao, A.; Ding, R.; Zhi, C.; He, J. Quenching and partitioning steel produced through hot rolling, direct quenching and annealing. Mater. Sci. Technol. 2016, 32, 1605-1612. [CrossRef]

34. Takahashi, M.; Bhadeshia, H.K.D.H. A Model for the Microstructure of Some Advanced Bainitic Steels. Mater. Trans. 1991, 32, 689-696. [CrossRef]

35. Jacques, P.; Delannay, F.; Ladriere, J. On the influence of interactions between phases on the mechanical stability of retained austenite in transformation-induced plasticity multiphase steels. Metall. Mater. Trans. A 2001, 32, 2759-2768. [CrossRef]

36. Fonstein, N. Advanced High Strength Sheet Steels: Physical Metallurgy, Design, Processing, and Properties; Springer: New York, NY, USA, 2015; ISBN 978-3-319-37301-0.

37. Matlock, D.K.; Speer, J.G. Third Generation of AHSS: microstructure design concepts. In Microstructure and Texture in Steels; Springer: London, UK, 2009; pp. 185-205.

38. Zhu, R.; Li, S.; Karaman, I.; Arroyave, R.; Niendorf, T.; Maier, H.J. Multi-phase microstructure design of a low-alloy TRIP-assisted steel through a combined computational and experimental methodology. Acta Mater. 2012, 60, 3022-3033. [CrossRef]

39. He, B.B.; Hu, B.; Yen, W.H.; Cheng, G.J.; Wang, Z.K.; Luo, H.W.; Huang, M.X. High dislocation density-induced large ductility in deformed and partitioned steels. Science 2017, 357, 1029-1032. [CrossRef] [PubMed]

(C) 2018 by the authors. Licensee MDPI, Basel, Switzerland. This article is an open access article distributed under the terms and conditions of the Creative Commons Attribution (CC BY) license (http://creativecommons.org/licenses/by/4.0/). 